\title{
Visualization of the Wisdom Cube Scientific Knowledge Space for Management and Leadership
}

\author{
Hannu Vanharanta ${ }^{\mathrm{i}, 2}$, Evangelos Markopoulos ${ }^{1,3}$ \\ ${ }^{1}$ School of Technology and Innovations, University of Vaasa, \\ Vaasa, Finland \\ ${ }^{2}$ Faculty of Engineering Management, Poznan University of Technology, \\ Poznan, Poland \\ ${ }^{3}$ Department of Business Management, UK, Hult International Business School, \\ London, UK \\ \{hannu@vanharanta.fi, evangelos.markopoulos@faculty.hult.edu\}
}

\begin{abstract}
Knowledge creation in organizations is crucial for their continuing existence. We are interested in querying and understanding what we know, how we know, what we do, and how we can justify everything so that we can lead and manage organizations. Therefore, it is important to follow the epistemological tradition, i.e., Episteme. This, however, is not enough, as reasoning has to go hand in hand with knowledge creation, i.e., Sophia, to know why things are done, what concepts are used, and what goals are possible. Techne, in turn, together with scientific and theoretical knowledge, develops new important technical and practical knowledge to make things happen. These three knowledge dimensions still lack real hands-on practical knowledge and wisdom, i.e., Phronesis, to show how and to know what should be decided. This research paper shows how the four different dimensions of knowledge can be used to understand the philosophical background of knowledge and wisdom creation.
\end{abstract}

Keywords: Cube · Episteme · Knowledge · Management · Leadership Phronesis $\cdot$ Philosophy $\cdot$ Sophia $\cdot$ Techne $\cdot$ Wisdom $\cdot$ Visualization

\section{Introduction}

The philosophers of the Ancient World (700 BCE - 250 CE) have inspired us by their writings to start thinking more deeply about the visualization of wisdom and knowledge [Buckingham]. The attempt here is now to put the basic principles in such a form that it is possible to show, in a practical way, how knowledge and wisdom are intertwined. Our aim is also to show how the definitions of the dimensions of wisdom give us the means to go further in our thinking to perceive and understand the important relationships between scientific, theoretical, technical, and practical knowledge. We can see this as a journey toward knowledge creation and wisdom. The starting point has been Ancient World philosophers and their thinking, but we do not have the same targets and goals as they had in their day [Buckingham, Magee]. Our target is more a practical understanding of knowledge creation and wisdom for management and leadership purposes because we have seen that there is so much to get out of the philosophers' 
basic thinking [Buckingham], which we can then turn to the benefit of modern management and leadership.

In this introduction, we would like to start with the Greek philosopher Pythagoras (born in Samos, lived c. 570 - 495/7 BCE) [Buckingham, Magee], who combined philosophy and mathematics. His most important discovery was the relationship between numbers and proportions, finding the way to numerical harmonies. Pythagoras's theorem reveals that shapes and ratios are governed by principles that can be discovered and shown in mathematical and graphical ways [Buckingham]. He was the man who was first able to apply arithmetic to geometrical concepts like the "square" and the "cube" [Magee]. Many graphs/harmonies are therefore possible and have also been used here as a kind of innovation platform.

Socrates (born in Athens, lived c. 469 - 399 BCE) has been referred to as the founder of moral philosophy as well as one of the founders of Western philosophy and thus has also been named the greatest and best-known philosopher of them all. During his active time, he developed the dialectic Socratic questioning method as a dialog between opposing views and understanding. He challenged people in philosophical discussions with fundamental questions concerning morality and politics. One of his pupils was Plato, who recorded the most important works of Socrates. [Buckingham, Magee].

Plato (born in Athens, lived c. $427-347$ BCE) described in his famous work 'the Republic', with his Allegory of the Cave, that understanding lies inside our minds as a world of ideas, or forms, which have nothing to do with the material world, and that our understanding and perception of this world are possible only through reason. According to Plato, this world of ideas is the true, actual "reality", not the world perceived by our senses. [Buckingham, Magee]

Aristotle (born in Stagira, lived 384 - 322 BCE), in turn, took a huge step forward by saying that Plato's theory of forms was wrong. Aristotle refuted Plato's theory with the Third Man argument by saying that if a man is a man because he has the form of a man, then a third form would be required to explain how man and the form of man are both men, and so on ad infinitum. Plato's background was in mathematics and Aristotle's as a researcher in the biological sciences. Aristotle based his thinking almost totally on observation, not on abstract concepts as Plato did. [Buckingham, Magee]

According to Aristotle [Aristotle], by relying on experiences of the world around us, through our senses, we get an idea of the characteristics of the world and can thus also understand inherent characteristics. After that, there are possibilities to study particular things and issues and conclude universal as well as immutable entities and truths [Buckingham]. All of the above concepts are somehow difficult for us to perceive, comprehend, and apply so that we obtain a holistic view of scientific, theoretical, and practical wisdom as well as knowledge generation. One view is that everything is in our minds; however, when it is articulated the other way around, i.e., that there are many different areas of knowledge that can be retrieved from data and information, people understand better how to create knowledge and where real knowledge exists.

Still, we have to go back and analyze what these philosophers teach us. There is much that their thinking can give us: especially how they view the different scientific, theoretical, methodological, and technical as well as practical knowledge needed to understand the world around us. Their thinking also helps us to see how we can challenge our perception and understanding as well as current knowledge, knowledge creation 
and the new knowledge that changes our way of thinking, and especially how to make progress in the context of management and leadership.

In the following sections, we try to show the creation of the wisdom space and the planes of wisdom with the formation of the Wisdom Cube to provide a practical way of understanding knowledge and wisdom. The starting point is the four dimensions of wisdom.

\section{The Dimensions of Wisdom}

Wisdom is difficult to define both thoroughly and briefly. Wisdom is somehow internal as well as external. When it is in humans it is internal, i.e., tacit, and when it is external it is explicit knowledge that exists somewhere. It is also important to understand what wisdom is not. It is not data and it is not information. It is created and comes from processing data and information through reasoning and through observation. Thus, it is connected to humans in a systematic way, as humans are systems. [Miller] Often, however, the processes in humans seem to be intuitive and automatic, based on the structure and operation of the human brain.

Episteme, Sophia, Techne, and Phronesis were the main dimensions when wisdom was defined and articulated by the Ancient Philosophers [Buckingham]. Each dimension has its own specific content, but the boundaries with the others are fuzzy by nature and it may be better to describe them in terms of degree. [Trillas, Wikipedia]

In the following, we try to form a certain harmony with the nature of these wisdom and knowledge concepts. If we place Episteme on the Y-axis, Sophia on the X-axis, and Techne on the Z-axis we obtain a three-dimensional cube (see Fig. 1), in which the diagonal represents the dimension of Phronesis, i.e., it has relationships and interrelationships with each of the three other dimensions and their components, concepts, and sub-concepts.

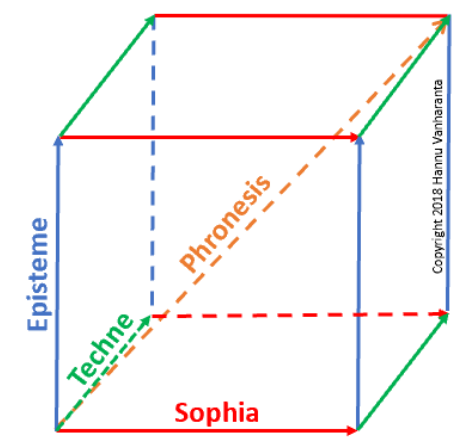

Fig. 1. The Wisdom Cube with the Four Dimensions of Wisdom

The Episteme dimension on the $\mathrm{Y}$-axis contains all scientific knowledge and can be defined as the scientific dimension of wisdom. Sophia on the X-axis contains all theoretical knowledge and shows the theoretical dimension of wisdom. In turn, Techne on the Z-axis represents technical knowledge and can be defined as the technical 
dimension of wisdom. The fourth (diagonal) dimension is the practical dimension of wisdom, i.e., Phronesis, which has connections, relationships, and interrelationships with each of the previous three dimensions of wisdom [Baehr]. The graphical presentation above (Fig. 1) gives us the Wisdom Cube. The Cube, with its components, will be delineated and depicted in more detail in the following chapters.

\subsection{Episteme - the Scientific Dimension of Wisdom}

As Aristotle said in his Nicomachean Ethics [Aristotle]:

"Scientific knowledge is about things that are universal and necessary, and the conclusions of demonstrations and all scientific knowledge follow from first principles (for scientific knowledge involves apprehension of rational ground). This being so, the first principle from which what is scientifically known follows cannot be an object of scientific knowledge, of art, or of practical wisdom; for that which can be scientifically known can be demonstrated, and art and practical wisdom deal with things that are variable."

This means that what is scientifically known can be demonstrated, and so things which are variable belong more to art and practical wisdom.

From the above, we can conclude that taking Episteme as a basis now demands a totally new type of teachable knowledge regarding management and leadership. We have to show and demonstrate better and better so that we obtain more universal as well as necessary knowledge for management and leadership purposes. We understand that in social sciences this is very demanding, but we see that it is nevertheless very natural and also practical to take the Episteme dimension and direction into consideration, especially if we use the other wisdom dimensions of Sophia, Techne, and Phronesis (see Fig. 2). A better scientific touch supports and improves the other areas of knowledge and wisdom.

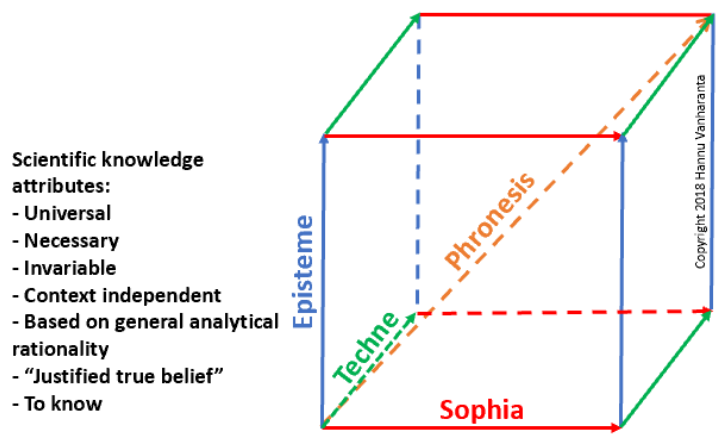

Fig. 2. Episteme - the Scientific Dimension of Wisdom 
In the management and leadership context, Episteme, the scientific dimension of wisdom, is therefore important; however, we cannot follow principles which are valid in the natural sciences like physics, chemistry, etc. We can only apply scientific knowledge in this management and leadership context and suppose that what we know is not even capable of being otherwise [Aristotle]. Therefore, the aspiration of scientific knowledge, Episteme, is also a necessity in this context. However, we understand that there are difficulties finding knowledge that is context-independent, invariable, necessary, and universal. The knowledge created is based normally on general analytical rationality. The target is to know and to create knowledge, i.e., "justified true belief", that is as close as possible to the demands of Episteme.

\subsection{Sophia - the Theoretical Dimension of Wisdom}

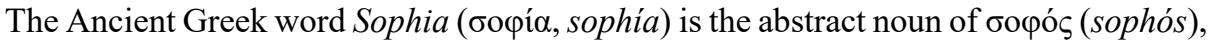
which has been variously translated by the words "clever, skillful, intelligent, wise" [Wikipedia], all of which characterize humans. Sophia has also been described with a wider conception as the theoretical dimension of wisdom [Baeher]. Theoretical knowledge, in turn, has been defined as knowledge of "why" something is true. This means that it is necessary to find explanations to state why certain truths are true. A deep understanding is then necessary, which requires reasoning concerning universal truths. Abstract concepts, as well as different contexts, make this reasoning difficult and many times the results do not fulfill the requirements (see Fig. 3).

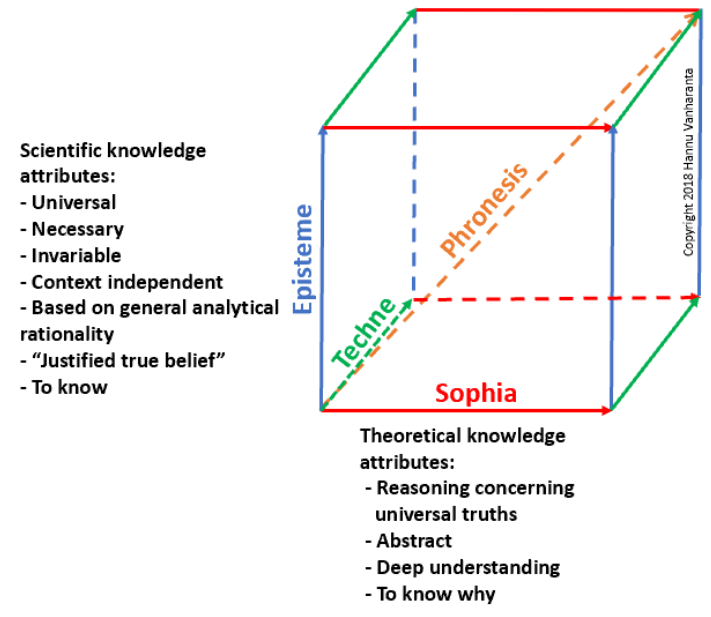

Fig. 3. Sophia - the Theoretical Dimension of Wisdom

In business management and leadership, the question "why" is extremely important. Many cause-and-effect relationships and interrelationships are difficult to observe without clever, skillful, intelligent, and wise managers and leaders. This, however, is not enough because knowledge also needs background theories, methodologies, and methods, which help to fix connections to quantitative data and qualitative information. 


\subsection{Techne - the Technical Dimension of Wisdom}

A very good definition of what Techne means comes from Aristotle's texts. He saw it as "representative of the imperfection of human imitation of nature" [Aristotle]. There are many examples that describe Techne as an activity, which is concrete, variable, and context-dependent. Carpentry has been mentioned in his texts as an example of Techne, as well as sciences like medicine and arithmetic. Often, Techne is thought of as more productive than theoretical, but Techne reveals its nature when people wish to obtain information concerning how to do something, i.e., technical know-how. It is also interesting that it fulfills the requirement of Episteme that it can be taught. This, in turn, is related to the people who are behind this knowledge and wisdom. Techne has connections to people who can make, know what is needed, know when the need exists, and also the context where something is needed. Techne is therefore very close to Phronesis, the practical dimension of wisdom (see Fig. 4).

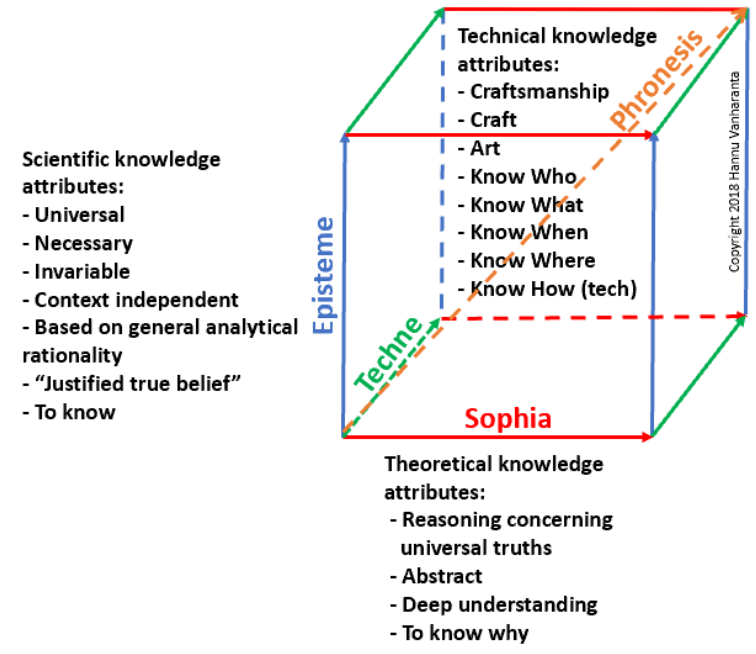

Fig. 4. Techne - the Technical Dimension of Wisdom

Techne also has connections with communication, since people are connected to their cultures and communicate what they are going to do or make. Human ability, capacity, commitment, and motivation show what a person is going to do and make. Techne aims at deeds where activity or making leads to an end or an end product. Techne is close to the terms technique, technical, and technology, leading to production activities, processes, as well as other mechanical or material components of the real world. [Aristotle] 


\subsection{Phronesis - the Practical Dimension of Wisdom}

Practical wisdom, Phronesis, is the fourth dimension of wisdom in the Wisdom Cube. It is an Ancient Greek word for a type of wisdom or intelligence (Ancient Greek: $\varphi \rho o ́ v \eta \sigma \check{\iota}$, translit. phrónēsis) [Wikipedia]. In his book, Nicomachean Ethics, Aristotle approaches Phronesis separately as one important area of wisdom [Aristotle]. It is more action-oriented but also includes the capability of rational thinking (see Fig. 5).

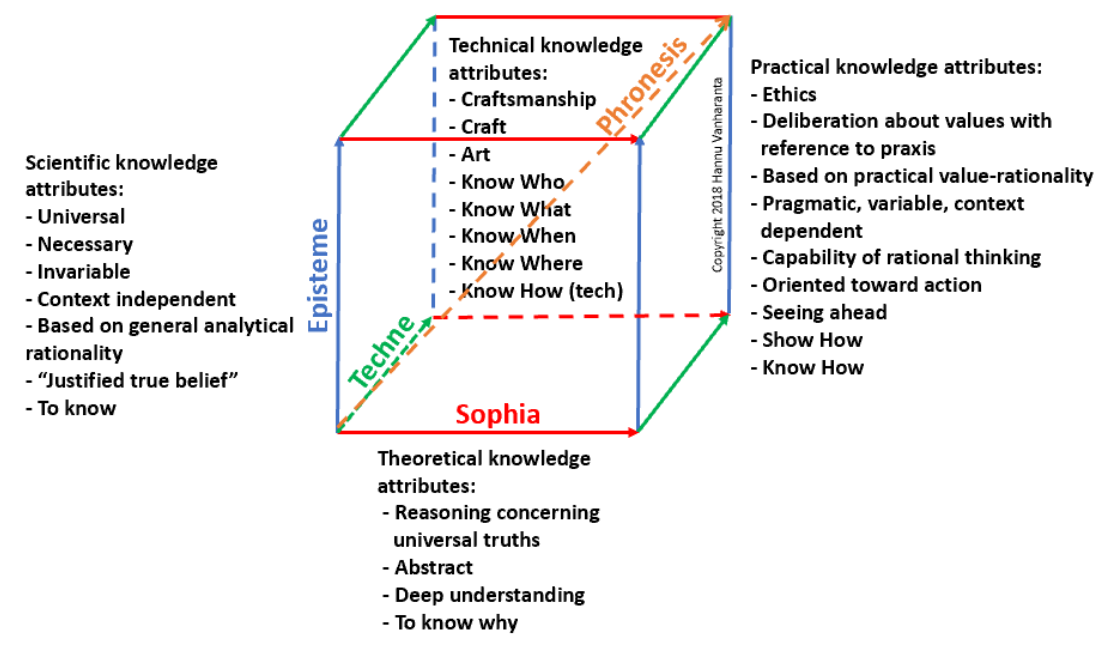

Fig. 5. Phronesis - the Practical Dimension of Wisdom

Phronesis is based on practical value-rationality and the created knowledge is variable (not invariable) because it is very much a context- and situation-dependent dimension of wisdom. Phronesis emphasizes deliberation about ethics and values with reference to practical needs. In business management and leadership, added and shared values constitute increased value, which the organization can produce for humankind with its human as well as its fixed assets.

One sub-dimension of Phronesis is looking ahead to the future, i.e., the "power of foresight" [Aristotle], which is something which people trust to be important in their current situation. Many times this wisdom emerges when people know how and also when they are capable of showing how. Much of this wisdom and knowledge is connected to intuitive thinking in a specific context and situation and so we understand that Phronesis has connections to Episteme, Sophia, and Techne. Its pragmatic nature serves people well and deliberation of ethics and values keep it close to daily life. This dimension of wisdom is therefore very important in daily management and leadership when deep understanding and deliberation are needed.

"Practical wisdom, on the other hand, is concerned with things human and things about which it is possible to deliberate; for we say this is above all the work of the man of practical wisdom, to deliberate well, but no one deliberates about things invariable, nor about things which have not an end, and that a good that can brought about by action". [Aristotle] 
Aristotle also teaches us by saying that practical wisdom needs a real understanding of particulars and this wisdom lies in people who have experience, and who are more practical than those who only emphasize universal knowledge and understanding [Aristotle]. This means that good and high-level practice should be focused on particulars. At the end of this section on the practical dimension of wisdom, it is worth referring to Aristotle when he comments that learning is called understanding when it means the exercise of the faculty of knowledge. [Aristotle]

\section{The Planes of Wisdom}

The planes of wisdom have been created with three vectors of wisdom as well as with the cube concept presented in Chapter 2. Each of the planes of the cube represents different areas of wisdom; however, in a way that with each vector we get two planes which have the same content. The planes of the constructed Cube of Wisdom are thus as follows: the Plane of Scientific and Technical Wisdom, the Plane of Scientific and Theoretical Wisdom, and the Plane of Theoretical and Technical Wisdom (see Fig. 6).

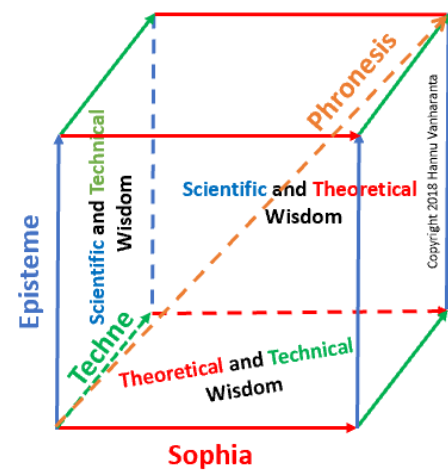

Fig. 6. The Planes of Wisdom

Inside the Planes of Wisdom there is the current Universe of Wisdom, i.e., all the wisdom humans have created during their existence. This is the wisdom and knowledge that humankind has, and it also describes the Space of Wisdom with its system boundaries and content. The Space of Wisdom is expanding and growing continuously in three directions (see Fig. 6). Outside the Space of Wisdom is the unknown, which is not yet available to us. Aristotle described this unknown in his Nicomachean Ethics, Book VI, 3, as follows:

"We all suppose that what we know is not even capable of being otherwise; of things capable of being otherwise we don't know, when they passed outside our observation, whether they exist or not." [Aristotle]

This unknown may be revealed to us in the future if we work hard and can make observations of the unknown. What then becomes known can be taught and will be the object of new learning and understanding.

Regarding management and leadership, the Wisdom Space of Management and Leadership has its own boundaries and its own planes and dimensions of wisdom. The 
categories and contexts of the Wisdom Space frame and shape many areas of wisdom and knowledge, depending on the context in question.

In the following, a short description of each of the Planes of Wisdom is presented.

\subsection{The Plane of Scientific and Theoretical Wisdom}

The Plane of Scientific and Theoretical Wisdom has two different wisdom dimensions and directions, i.e., the scientific Episteme and the theoretical Sophia. Scientific wisdom is what we know and what has been revealed through observations and experiments. Theoretical wisdom, in turn, is more a kind of deep understanding and utilizes answers to many "why" questions. Knowing why the world is like it is reveals the basic facts behind and reasoning concerning universal truths. This theoretical dimension can be abstract or concrete. To perceive and understand the content demands great capacity of the people who concentrate on creating more theoretical knowledge and wisdom. We can imagine this kind of knowledge through the planes of the Wisdom Cube, where we have real facts, truths, as well as theories that give us a new deep understanding of the world around us. We can also understand that interpreting problems with the help of reasoning in a given situation with a good theory can provide many new opportunities to find meaningful solutions to the problems in question. In social sciences, which is our context, namely management and leadership, we have to consider the fact that true knowledge might be difficult to achieve because the theories of management and leadership are often fuzzy and not as accurate as strict theoretical requirements demand. In physics and chemistry and other natural sciences, the situation is totally different and then the scientific and therefore the Plane of Scientific and Theoretical Wisdom has a different nature and characteristics. [Aristotle]

\subsection{The Plane of Theoretical and Technical Wisdom}

The Plane of Theoretical and Technical Wisdom also has two dimensions: the theoretical Sophia and the technical Techne. Both the dimensions and directions have created an important area of wisdom and knowledge. Many technical discoveries are based on good theories; also the craftsmanship thinking in the Techne dimension provides possibilities to understand the practical side of the theories. Questions like know who, know what, know when, and know where, know how, etc. also fit extremely well with the theoretical reasoning concerning universal truths and abstract concepts. Craft and art aspects are different in Techne, but activating and making describe this direction very well [Aristotle]. Deep understanding through theoretical discussions and also making empirical tests will widen the Plane of Theoretical and Technical Wisdom.

\subsection{The Plane of Scientific and Technical Wisdom}

The third plane is the Plane of Scientific and Technical Wisdom. There are also two dimensions and directions, i.e., Episteme and Techne. The increase of scientific knowledge has given the technical side vast new opportunities in the modern world. Facts from scientific knowledge help craftsmanship and engineering to flourish, generating innovative and ever better products and services for humankind. In the modern 
era, we have experienced many new scientific discoveries, which have been turned into everyday products or services. In recent times computer sciences have taken the leading position to change the world, and help us solve complex multi-variable problems in many scientific, theoretical, and practical areas and contexts.

\section{The Space of Wisdom}

All three planes are components in building the Space of Wisdom. It is understood that by determining the characteristics and faculties of each plane we can construct a large space, which may have huge amounts of connections and interconnections. This kind of network is maintained and supported with the data and information we have put into the system and the outgoing knowledge can be extracted by the people using the data and information within. To obtain a holistic view of the dimensions, planes, and the Space of Wisdom, we have integrated everything into a single diagram (see Fig. 7).

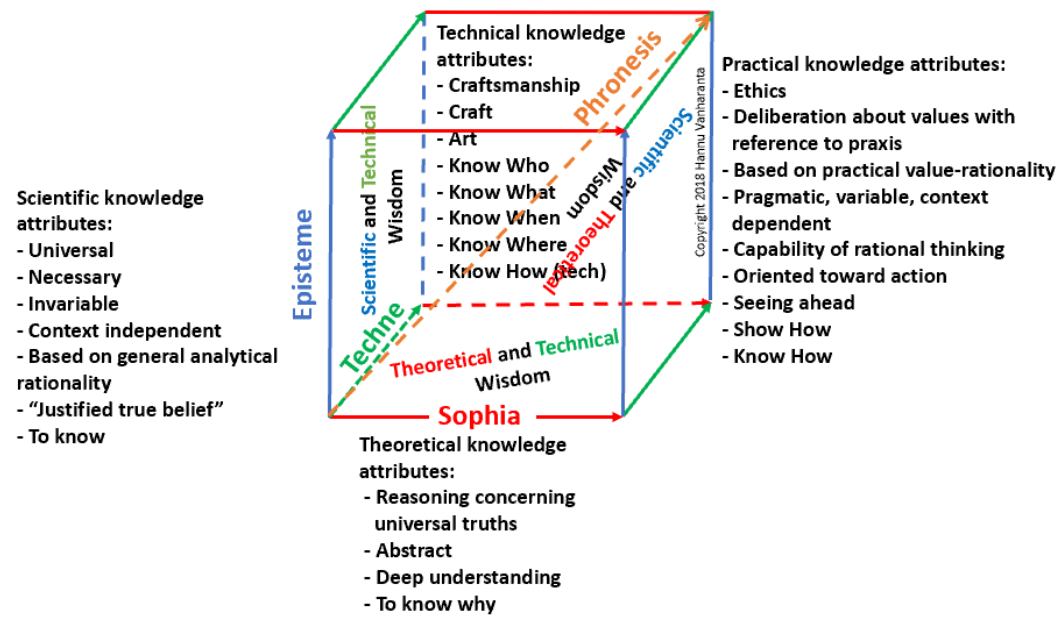

Fig. 7. The Space of Wisdom with the Dimensions and Planes of Wisdom

Fig. 7 shows very clearly that breaking down the construct into different characteristics helps us understand the nature of wisdom and it also shows how important it is to use this created knowledge for teaching purposes in the management and leadership context. Fig. 7 allows us to go further and penetrate deeper into the secrets of business knowledge in the specific context we have taken. Humans behave as active members inside this Space of Wisdom, as entities, i.e., as living systems. [Miller]

The Planes and Space of Wisdom show clearly that the Ancient Philosophers reached a level of understanding that gives us great opportunities to see ourselves as members and owners of that 'big wisdom'. The degree of wisdom in each plane can describe an individual's position in the overall universal Space of Wisdom. A strong scientific, theoretical, and technical education throughout the Planes of Wisdom is one important path for managers and leaders to attain a strong position in their organization. For cross- 
scientific purposes as well as for teams and teamwork, it is important to concentrate on a verified and validated education, which increases knowledge creation in all dimensions. This process leads to high-level outputs in daily work on the individual level as well as on the collective level.

\section{$5 \quad$ Discussion and Conclusions}

This research is scientific, theoretical, technical, as well as practical for management and leadership purposes. The research derived from a keen interest in philosophy as well as management and leadership. The ideas for the content came from the discussions between the authors over many years as well as writing about new management and leadership concepts in different specific areas. The three-dimensional model, the Wisdom Cube, has been an integral part of our thinking for a number of years now and we consider that three-dimensional thinking has helped us immensely in understanding many new business ontologies as well as real business constructs and concepts.

The construct of the Wisdom Cube with the Dimensions of Wisdom as well as the Planes of Wisdom has helped us to demonstrate the concepts of knowledge areas in Episteme, Sophia, Techne, and Phronesis. The construct has also provided a strong base for further analysis of what it means in the context of management and leadership.

As a scientific contribution (Episteme), we can conclude that the visualization of the Wisdom Cube helps to understand the creation of scientific knowledge. The attributes of scientific knowledge clarify the requirements of "justified true belief", which are clear demands for knowledge creation in the management and leadership context.

The theoretical contribution (Sophia) in this research helps us to understand the attributes of theoretical knowledge. The attribute "know why" focuses the reasoning process on answering why our management and leadership constructs, concepts, and variables produce important information for knowledge creation in specific business situations.

The technical dimension of wisdom (Techne) and its relations to the other wisdom dimensions can be seen as an enabler. Many new scientific theories see the light of day through developed technologies. Techne transforms the scientific as well as theoretical discoveries and innovations for practical use. During recent years we have experienced many new technology services and products which help humankind in many ways. We can say that Techne converts human wisdom into practice.

The practical visualization of wisdom presented here, the Dimension(s) and Plane(s) of Phronesis, can be used first for education purposes. The attributes of Phronesis are highly suitable for Ph.D. students and Master's students of business management and leadership. The Wisdom Cube, as a whole, is a clear metaphor, which students can remember easily, and which can hold the content as a foundation for their studies in the business context. The Cube is also relevant for managers and leaders already working in business. It shows in a practical way how important it is to continuously increase personal as well as collective knowledge creation in their organizations. The Phronesis attributes focus on a detailed deliberation about values from many directions. They also cover a large area of knowledge creation to understand what to do now, how to do it, as well as to see into the future so that the decision makers can support, lead, and decide the best possible paths for the characteristics of their own company. Important questions 
in perceiving, in deep understanding, as well as in knowledge creation are: Where are we now? Why are we here? Where should we be? and Are we getting there? To quote Aristotle [Aristotle]: "Wisdom is intuitive reason combined with scientific knowledge."

\section{References}

1. Buckingham, W., King, Peter J., Burnham, D., Weeks, M., Hill, C., and Marenbon, J. The Philosophy Book. Dorling Kindersley Ltd. London 352 p. (2011)

2. Magee, B.: The Story of Philosophy, Dorling Kindersley Ltd. London, 240 p. (2016)

3. Miller, J., G., Living Systems, McGraw-Hill Inc., 1102 p. (1978)

4. Aristotle: Nicomachean Ethics. Translated by Ross, W., D. Batoche Books, Kitchener, Book VI, 91--105 (1999)

5. Baehr, J.: "SOPHIA: Theoretical Wisdom and Contemporary Epistemology. In: Timpe, K., Boyd, C. (eds.) Virtues and their Vices. pp. 303-323 Oxford University Press, Oxford (2014)

6. https://en.wikipedia.org/wiki/Sophia_(wisdom)

7. https://en.wikipedia.org/wiki/Phronesis

8. Trillas, E.: Lotfi A. Zadeh: On the man and his work, Scientia Iranica, D 18 (3), pp. 574-579 (2011)

9. https://en.wikipedia.org/wiki/Lotfi_A._Zadeh 